\title{
Additive effects of nutritional supplementation, together with bisphosphonates, on bone mineral density after hip fracture: a 12-month randomized controlled study
}

Clinical Interventions in Aging

7 July 2014

Number of times this article has been viewed

\author{
Lena Flodin ${ }^{1,2}$ \\ Maria Sääf ${ }^{3}$ \\ Tommy Cederholm ${ }^{4}$ \\ Amer N Al-Ani ${ }^{2,5}$ \\ Paul W Ackermann ${ }^{5,6}$ \\ Eva Samnegård ${ }^{7}$ \\ Nils Dalen ${ }^{7}$ \\ Margareta Hedström ${ }^{2,5}$ \\ 'Department of Geriatric Medicine, \\ Karolinska University Hospital \\ Stockholm, Sweden; ${ }^{2}$ Department of \\ Clinical Science, Intervention, and \\ Technology, Karolinska Institutet, \\ Stockholm, Sweden; ${ }^{3}$ Department \\ of Endocrinology, Metabolism, and \\ Diabetes, Karolinska University \\ Hospital, Stockholm, Sweden; \\ ${ }^{4}$ Department of Public Health and \\ Caring Sciences, Clinical Nutrition \\ and Metabolism, Uppsala University, \\ Uppsala, Sweden; ${ }^{5}$ Department of \\ Orthopedics, Karolinska University \\ Hospital, Stockholm, Sweden; \\ ${ }^{6}$ Department of Molecular Medicine \\ and Surgery, Karolinska Institutet, \\ Stockholm, Sweden; ${ }^{7}$ Department \\ of Clinical Science, Division of \\ Orthopedics, Karolinska Institutet, \\ Danderyd Hospital, Stockholm, \\ Sweden
}

Background: After a hip fracture, a catabolic state develops, with increased bone loss during the first year. The aim of this study was to evaluate the effects of postoperative treatment with calcium, vitamin D, and bisphosphonates (alone or together) with nutritional supplementation on total hip and total body bone mineral density (BMD).

Methods: Seventy-nine patients (56 women), with a mean age of 79 years (range, 61-96 years) and with a recent hip fracture, who were ambulatory before fracture and without severe cognitive impairment, were included. Patients were randomized to treatment with bisphosphonates (risedronate $35 \mathrm{mg}$ weekly) for 12 months (B; $\mathrm{n}=28$ ), treatment with bisphosphonates along with nutritional supplementation ( $40 \mathrm{~g}$ protein, $600 \mathrm{kcal}$ daily) for the first 6 months ( $\mathrm{BN} ; \mathrm{n}=26)$, or to controls $(\mathrm{C} ; \mathrm{n}=25)$. All participants received calcium $(1,000 \mathrm{mg})$ and vitamin D3 (800 IU) daily. Total hip and total body BMD were assessed with dual-energy X-ray absorptiometry at baseline, 6, and 12 months. Marker of bone resorption C-terminal telopeptide of collagen I and 25-hydroxy vitamin D were analyzed in serum.

Results: Analysis of complete cases (70/79 at 6 months and 67/79 at 12 months) showed an increase in total hip BMD of $0.7 \%$ in the $\mathrm{BN}$ group, whereas the $\mathrm{B}$ and $\mathrm{C}$ groups lost $1.1 \%$ and $2.4 \%$ of BMD, respectively, between baseline and 6 months ( $P=0.071$, between groups). There was no change in total body BMD between baseline and 12 months in the $\mathrm{BN}$ group, whereas the $\mathrm{B}$ group and $\mathrm{C}$ group both lost $\mathrm{BMD}$, with $\mathrm{C}$ losing more than $\mathrm{B}(P=0.009)$. Intention-totreat analysis was in concordance with the complete cases analyses.

Conclusion: Protein-and energy-rich supplementation in addition to calcium, vitamin D, and bisphosphonate therapy had additive effects on total body BMD and total hip BMD among elderly hip fracture patients.

Keywords: hip fracture, nutritional supplementation, bisphosphonates, bone mineral density

\section{Introduction}

Inadequate intake of protein and total calories, leading to malnutrition, is common among hip fracture patients. ${ }^{1,2}$ After a hip fracture, a catabolic state develops, characterized by increased loss of bone mineral density (BMD) during the first year. ${ }^{3-5}$ Because protein is an important structural component of bone and previous studies have reported a positive association between protein intake and $\mathrm{BMD} /$ bone mineral content, ${ }^{6-8}$ it is tempting to hypothesize that protein and energy supplementation may slow down postoperative bone loss. One previous study showed that hip fracture patients who received postoperative supplemental protein suffered less loss of BMD in the proximal femur
Correspondence: L Flodin Department of Geriatric Medicine R94, Karolinska University Hospital SE-14I 86, Stockholm, Sweden

Email lena.flodin@karolinska.se 
compared with controls at 12 months. ${ }^{9}$ Otherwise, there are few studies that have investigated the effect of nutritional supplementation on BMD after hip fractures.

Bisphosphonates are the most widely used drugs for treatment of osteoporosis and have been shown to reduce the risk for hip fracture. ${ }^{10,11}$ Risedronate, which was used in the present study, has previously been shown to increase BMD of the femoral neck and femoral trochanter in osteoporotic women aged 80 years and older after 6 months of treatment. ${ }^{12}$ Risedronate has not been studied for secondary prevention of bone loss in old adults after a hip fracture. However, beneficial effects on total hip BMD after hip fracture have been demonstrated, using zoledronic acid together with calcium and vitamin D. ${ }^{13}$

The primary aim of this study was to investigate whether postoperative treatment with a combination of protein-rich formula and bisphosphonates can reduce BMD loss after hip fracture better than bisphosphonates alone. Secondary aims were to study treatment effects on the bone resorption marker C-terminal telopeptide of collagen I (serum CTX-I), serum levels of 25-hydroxy vitamin D (25OHD), and parathyroid hormone (PTH).

\section{Methods}

\section{Patients}

The study included a total of 79 patients with a mean age of 79 years (standard deviation, 9; range, 61-96 years) and a history of recent hip fracture (femoral neck or trochanteric) who were admitted to any of the four university hospitals in Stockholm. Inclusion criteria were age 60 years or older, no severe cognitive impairment (Short Portable Mental Questionnaire ${ }^{15}$ [see below] score, $\geq 3$ ), ambulatory before fracture, and body mass index $28 \mathrm{~kg} / \mathrm{m}^{2}$ or lower. Exclusion criteria were pathological fractures and bisphosphonate treatment within the last year. Patients with alcohol/drug abuse or overt psychiatric disorders were excluded. Also excluded were patients with abnormal hepatic or renal laboratory parameters such as serum-alanine aminotransferase or serum-aspartate-aminotransferase twice the normal reference range or higher, respectively; serum-creatinine levels higher than $130 \mu \mathrm{mol} / \mathrm{L}$ or glomerular filtration rate lower than $30 \mathrm{~mL} /$ minute; or with bone metabolic disorders such as primary hyperparathyroidism, osteogenesis imperfecta, Paget's disease, or myeloma. Patients with lactose intolerance, dysphagia, esophagitis, gastric ulcer, or malignancy were also excluded, as were patients with diabetes mellitus associated with nephropathy or retinopathy and patients with active iritis or uveitis.

\section{Study design and intervention}

Eligible patients who agreed to participate were randomized into three groups in blocks of twelve, using a sealed envelope technique, thereby ensuring equal distribution of patients in the three treatment groups at each center. Patients were followed-up for 12 months. All participants received $1,000 \mathrm{mg}$ calcium and $800 \mathrm{IU}$ vitamin D3 daily. The first group received $35 \mathrm{mg}$ risedronate (Optinate ${ }^{\circledR}$ Septimum; Sanofi AB, Warner Chilcott, Weiterstadt, Germany) once weekly for 12 months $(\mathrm{B} ; \mathrm{n}=28)$. The second group received $35 \mathrm{mg}$ risedronate once weekly for 12 months plus a nutritional supplement (Fresubin ${ }^{\circledR}$ protein energy drink; Fresenius Kabi, Bad Homburg, Germany) during the first 6 months after hip fracture $(B N ; n=26)$. The patients in the third group served as controls $(\mathrm{C} ; \mathrm{n}=25)$ and received calcium and vitamin D3 alone (Calcichew D3 ${ }^{\circledR}$; Takeda Pharmaceutical Company Limited, Osaka, Japan) for 12 months.

The supplement contained $150 \mathrm{kcal}$ and $10 \mathrm{~g}$ protein/ $100 \mathrm{~mL}$ milk-based protein (80\% casein and $20 \%$ whey). Patients were prescribed $200 \mathrm{~mL}$ twice daily, totaling $600 \mathrm{kcal}$ with $40 \mathrm{~g}$ protein. Each study center was staffed by one physician and a trial nurse. The trial team was responsible for the randomization process, collection of morning blood samples 1-3 days postfracture, and ensuring that dual-energy X-ray absorptiometry (DXA) and all other examinations were carried out during the hospital stay.

Pharmacologic treatment and nutritional supplementation began as soon as patients were stable from a cardiovascular standpoint, able to take food by mouth, and able to sit in an upright position for 1 hour after taking their tablets.

Patients were instructed both verbally and in writing to take bisphosphonate 30 minutes before food and other medications. They were examined at baseline and again during follow-up at 6 and 12 months. About once a month, the research nurses interviewed patients by telephone regarding compliance, food intake, pain, and general state of health.

The study was conducted in compliance with the Helsinki Declaration and was approved by the local ethics committee in Stockholm. All participants provided written informed consent. (ClinicalTrials.gov: NCT01950169).

\section{Measurements}

BMD was measured by DXA, using either Hologic (Hologic, Inc., Waltham, MA, USA) or Ge Lunar (Madison, WI, USA) densitometers. BMD on the uninjured side (total hip) was assessed, as well as total-body BMD. Results were expressed as areal density $\left(\mathrm{g} / \mathrm{cm}^{2}\right)$ and as standard deviation in relation to both mean value among healthy young individuals 
(T-score) and mean value of age- and sex-matched adults (Z-score). The precision error was $0.010 \mathrm{~g} / \mathrm{cm}^{2}$ and $0.007 \mathrm{~g} / \mathrm{cm}^{2}$, respectively, for the total hip and total body BMD. To compensate for variation in BMD measurements among different centers and densitometers, equations to standardize BMD were used to create standardized bone mineral density (sBMD) in milligrams per square centimeter for the total hip result. ${ }^{14}$ Plasma-calcium ( $\left.\mathrm{mmol} / \mathrm{L}\right)$, plasma-albumin $(\mathrm{g} / \mathrm{L})$, and serum-PTH (ng/L) were analyzed according to standard hospital laboratory procedure for each center. Serum-25OHD (nmol/L) was analyzed at baseline and again after 12 months, using chemiluminescence immunoassays (Liason ${ }^{\circledR} 25 \mathrm{OH}$ vitamin D Total Assay; DiaSorin Inc., Stillwater, MN, USA). To evaluate changes in bone turnover, serum CTX-I (ng/L) was analyzed at baseline and at 12 months, using the BetaCrossLaps assay (Roche Diagnostics GmbH, Mannheim, Germany), a two-site immunometric (sandwich) assay based on electro-chemiluminescence detection. The interassay coefficient of variation was less than $20 \%$. Patient height, weight, and body mass index were monitored. Height was measured in the supine position. Weight was calculated from total mass (lean, fat, and bone mineral content), obtained through DXA measurements. The examination also included an appraisal of cognitive function using the Short Portable Mental Questionnaire, including ten simple questions. ${ }^{15}$

\section{Statistical methods}

Calculations were performed using SPSS 22.0 for Windows (IBM Corporation, Armonk, NY, USA). Descriptive statistics included mean, standard deviation, median, range, and percentage. Differences between the three randomized treatment groups were analyzed using analysis of covariance (ANCOVA). Covariates used in the analysis of BMD were age, sex, total mass, and baseline BMD. Age and baseline value were used as covariates in the analysis of serum-25OHD. Baseline value was the only covariate used in the analysis of serum-PTH. The covariates used in the analysis of serum-CTX-I were age, sex, and baseline value. Normal distribution of serum-CTX-I values was achieved by transformation, using a logarithmic scale. A paired-samples Student's $t$-test was used to compare differences in serum-CTX-I within each group between baseline and follow-up. In addition to analysis of complete cases, an intention-to-treat analysis was carried out ${ }^{16}$ in accordance with Consolidated Standards of Reporting Trials guidelines. ${ }^{17}$

\section{Results}

No significant differences in baseline characteristics were found among the three treatment groups, other than the need for walking aids (Table 1). A total of $67(85 \%)$ of the original 79 patients presented for the final follow-up; Figure 1 shows a patient flowchart. Among patients who dropped out, average age was 87 years (standard deviation, 5; range, 78-94 years), mean value of total hip BMD was $0.650 \mathrm{~g} / \mathrm{cm}^{2}$ (standard deviation, 0.103 ), and total body BMD was $0.943 \mathrm{~g} / \mathrm{cm}^{2}$ (standard deviation, 0.147).

\section{Treatment adherence}

Among the control patients, 17 of 24 patients who presented at 12 months took calcium and vitamin D as prescribed. In group B, 18 of 25 presenting patients took their daily dose of calcium and vitamin $\mathrm{D}$, and 18 of 25 took the bisphosphonate as stipulated. In group $\mathrm{BN}$, seven of 18 corresponding patients complied with the drugs and nutritional supplement prescription; the remaining eleven patients reported an intake of half the prescribed nutritional supplement. Three of these patients also reported a lower intake of prescribed bisphosphonate, and two took only half the prescribed daily dose of calcium and vitamin D. In total, 15 patients in the BN group took the bisphosphonate as stipulated.

Three patients in the control group and two in the group B reported gastrointestinal complaints (either constipation or diarrhea). A dose reduction was made for one patient with hypercalcemia in group $\mathrm{C}$.

\section{Effects on BMD and bone turnover}

Seventy-nine patients were measured by DXA at inclusion, 68 patients at 6 months, and 66 at 12 months. Because of a total hip replacement on the uninjured side, nine patients could not be measured at the hip.

During the first 6 months, total hip BMD increased by $0.7 \%$ in the $\mathrm{BN}$ group, whereas groups $\mathrm{B}$ and $\mathrm{C}$ showed losses of $1.1 \%$ and $2.4 \%$, respectively $(P$ by ANCOVA $=0.071$; Table 2; Figure 2).

On average, there was no loss in total body BMD between baseline and 12 months in the BN group (Table 2). Moreover, both the $\mathrm{B}$ and $\mathrm{C}$ groups lost $\mathrm{BMD}$, and this loss was greater among controls than in group $\mathrm{B}(P=0.009$; Table 2 ; Figure 3).

There was a trend for difference between groups, according to change in the bone resorption marker serum-CTX-I ( $P=0.055$; Table 2). Within-group analysis showed a significant decrease in the serum-CTX-I marker of $33 \%$ and $36 \%$ in groups $\mathrm{B}$ and $\mathrm{BN}$, respectively $(P<0.001)$, whereas the smaller decrease of $12 \%$ in the $\mathrm{C}$ group was not significant $(P=0.77)$. 
Table I Patients and group characteristics at baseline

\begin{tabular}{|c|c|c|c|c|}
\hline & $\begin{array}{l}\text { Group C } \\
(n=25)\end{array}$ & $\begin{array}{l}\text { Group B } \\
(n=28)\end{array}$ & $\begin{array}{l}\text { Group BN } \\
(n=26)\end{array}$ & $P$-value \\
\hline Age & & & & 0.477 \\
\hline Mean (SD) & $78(I I)$ & $80(9)$ & $81(8)$ & \\
\hline Median (range) & $75(6 \mid-96)$ & $82(63-94)$ & $82(62-93)$ & \\
\hline Sex, n (\%) & & & & 0.630 \\
\hline Women & $19(76)$ & $18(64)$ & $19(73)$ & \\
\hline Men & $6(24)$ & $10(36)$ & $7(27)$ & \\
\hline Type of fracture, $n(\%)$ & & & & 0.910 \\
\hline Femoral neck & II (44) & $12(43)$ & $10(38)$ & \\
\hline Trochanteric & $14(56)$ & $16(57)$ & $16(62)$ & \\
\hline Surgical method, n (\%) & & & & 0.850 \\
\hline Internal fixation & $21(84)$ & $25(89)$ & $23(88)$ & \\
\hline Arthroplasty & $4(16)$ & $3(11)$ & $3(12)$ & \\
\hline Weight, kg, mean (SD) & $60.7(12.6)$ & $67.8(13.3)$ & $61.7(8.8)$ & 0.093 \\
\hline Total mass, kg, mean $(\mathrm{SD}) *$ & $60.2(12.8)$ & $66.9(13.3)$ & $61.4(9.8)$ & 0.166 \\
\hline $\mathrm{BMI}, \mathrm{kg} / \mathrm{m}^{2}$, mean (SD) & $22.4(2.6)$ & $24.0(2.9)$ & $22.7(3.4)$ & 0.115 \\
\hline BMD total hip, $\mathrm{g} / \mathrm{cm}^{2}$, mean $(\mathrm{SD})$ & $0.702(0.157)$ & $0.725(0.138)$ & $0.701(0.133)$ & 0.815 \\
\hline sBMD total hip, $\mathrm{mg} / \mathrm{cm}^{2}$, mean (SD) & $662(153)$ & $688(138)$ & $662(128)$ & 0.803 \\
\hline T-score total hip, mean (SD) ${ }^{t}$ & $-2.5(1.1)$ & $-2.4(1.0)$ & $-2.6(1.1)$ & 0.894 \\
\hline Z-score total hip, mean (SD) & $-1.2(1.1)$ & $-1.0(0.7)$ & $-0.9(1.2)$ & 0.613 \\
\hline BMD total body, $g / \mathrm{cm}^{2}$, mean (SD) & $0.958(0.149)$ & $0.988(0.169)$ & $0.985(0.134)$ & 0.699 \\
\hline Plasma-calcium, mmol/L, mean (SD) ${ }^{\dagger}$ & $2.27(0.11)$ & $2.24(0.12)$ & $2.25(0.10)$ & 0.593 \\
\hline Plasma-albumin, $g / L^{\ddagger}$ & $34(5)$ & $34(5)$ & $35(5)$ & 0.572 \\
\hline Serum-25OHD, nmol/L, mean (SD) ${ }^{\pi}$ & $5 I(2 I)$ & $46(18)$ & $42(20)$ & 0.254 \\
\hline Serum-parathyroid hormone, ng/L, mean (SD) ${ }^{\S}$ & $45(16)$ & $49(20)$ & $50(22)$ & 0.844 \\
\hline Serum-CTX-I, ng/L, mean (SD)** & $472(329)$ & $50 I(242)$ & $381(157)$ & 0.277 \\
\hline Walking aid, $\mathrm{n}(\%)$ & & & & 0.036 \\
\hline Independent or one stick & $24(96)$ & $19(68)$ & $20(77)$ & \\
\hline Two sticks or a frame & I (4) & $9(32)$ & $6(23)$ & \\
\hline Walking distance, n (\%) & & & & 0.691 \\
\hline Outdoor $0.5-2.0 \mathrm{~km}$ & $24(96)$ & $25(89)$ & $23(88)$ & \\
\hline Indoor only & I (4) & $3(I I)$ & $3(12)$ & \\
\hline
\end{tabular}

Notes: *Total mass (lean, fat and bone mineral content). ${ }^{\mathrm{T}}$-score; BMD expressed as standard deviation units related to the mean value for healthy young adults. T-score $\geq-1.0$ is considered to be normal, T-score $\leq-2.5$ is considered as osteoporosis. 'Z-score; age-and sex-matched BMD expressed as standard deviation units. ${ }^{\dagger}$ Plasma-calcium adjusted for albumin level, reference range: $2.20-2.60 \mathrm{mmol} / \mathrm{L}$. ${ }^{\ddagger}$ Plasma-albumin, reference range: 36-45 g/L. "Serum-25-hydroxy-vitamin D (serum-25OHD), reference range:

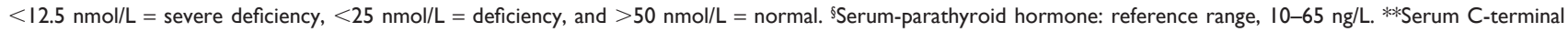
telopeptide of collagen I (serum-CTX-I), reference range in postmenopausal women is $<1,000 \mathrm{ng} / \mathrm{L}$, in men $50-70$ years of age is $<700 \mathrm{ng} / \mathrm{L}$, and in those aged $\geq 7 \mathrm{I}$ years is $<850 \mathrm{ng} / \mathrm{L}$.

Abbreviations: SD, standard deviation; BMI, body mass index; sBMD, standardized bone mineral density; C, control; B, bisphosphonates; BN, bisphosphonates along with nutritional supplementation.

\section{Levels of $25 \mathrm{OHD}$ and parathyroid hormone}

During the study, there was a mean increase in serum-25OHD of between $17 \mathrm{nmol} / \mathrm{L}$ and $20 \mathrm{nmol} / \mathrm{L}$ in all three groups. Mean serum-25OHD concentrations in groups B and $\mathrm{BN}$ were below normal (ie, $<50 \mathrm{nmol} / \mathrm{L}$ at baseline) but had normalized by the 12-month follow-up (Tables 1 and 2). In total, $59 \%$ of the patients had a baseline concentration of serum-25OHD that was lower than $50 \mathrm{nmol} / \mathrm{L}$. Among them, eleven had values lower than $25 \mathrm{nmol} / \mathrm{L}$. At the 12-month follow-up, $26 \%$ of the patients still had serum$25 \mathrm{OHD}$ concentrations that were lower than $50 \mathrm{nmol} / \mathrm{L}$. We identified lack of compliance in eleven of the 18 patients who failed to normalize their concentration of serum$25 \mathrm{OHD}$.

Mean serum-PTH remained in the normal range for all groups at inclusion and at the 6-month and 12-month follow-ups; no significant difference was found among the groups on any measurement occasion.

\section{Intention-to-treat analysis}

The primary analysis population was used to replace missing data, and the secondary analysis population was used as a sensitivity analysis and showed the following results. The percentage change in total hip BMD between baseline and 6 months was $+0.9 \%$ in the $\mathrm{BN}$ group and $-0.5 \%$ 


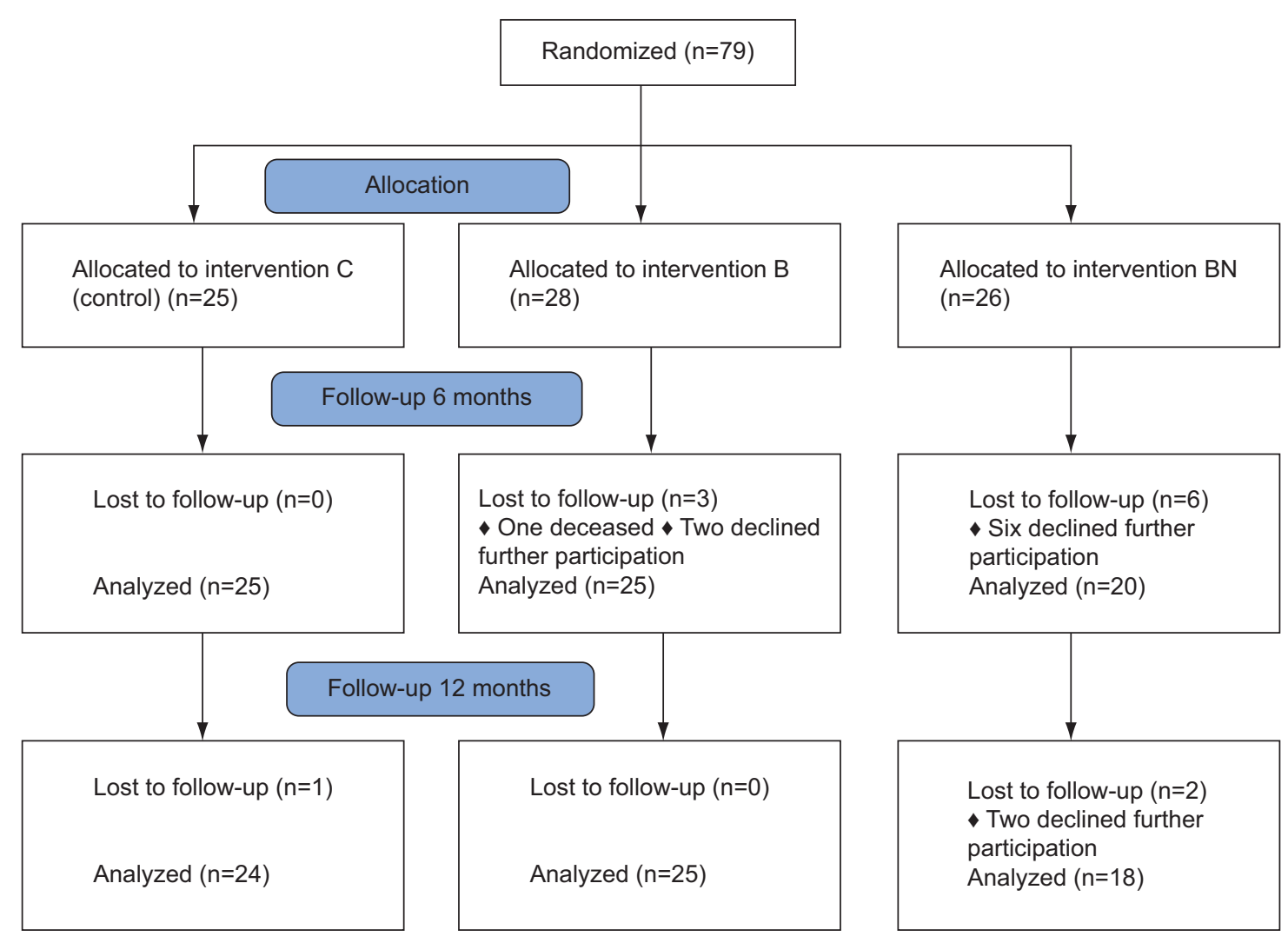

Figure I Flow chart of participants through the trial.

Abbreviations: $\mathrm{C}$, control; $\mathrm{B}$, bisphosphonates; $\mathrm{BN}$, bisphosphonates along with nutritional supplementation.

and $-2.7 \%$ in the $\mathrm{B}$ and $\mathrm{C}$ groups, respectively $(P=0.03)$. The corresponding changes between baseline and 12 months were $-0.8 \%$ for the $\mathrm{BN}$ group and $-1.7 \%$ and $-2.6 \%$ for the $\mathrm{B}$ and $\mathrm{C}$ groups, respectively $(P=0.279)$.

According to the sensitivity analysis, the percentage change in total body BMD between baseline and 6 months was $-0.7 \%$ for the $\mathrm{BN}$ group and $-0.7 \%$ and $-1.3 \%$ for the $\mathrm{B}$ and $\mathrm{C}$ groups, respectively $(P=0.436)$. Between baseline and 12 months, the percentage change in total body BMD was $-0.02 \%$ for the BN group and $-0.9 \%$ and $-1.6 \%$ for the $\mathrm{B}$ and $\mathrm{C}$ groups, respectively $(P=0.030)$.

The sensitivity analysis confirmed the trend indicated by the results, showing a more pronounced decrease in serumCTX-I in the $\mathrm{B}$ and $\mathrm{BN}$ groups than in the $\mathrm{C}$ group $(P=0.019)$. The sensitivity analysis was in line with the results for complete cases, showing no significant differences among the three groups in changes of serum-25OHD and serum-PTH at either 6- or 12-month follow-up.

\section{Discussion}

We found that nutritional supplementation, in addition to calcium, vitamin D, and risedronate, had a positive effect on total hip BMD and total body BMD in elderly patients with a recent hip fracture. An annual loss of $0.27 \%$ and $0.25 \%$ of total hip BMD in women and men, respectively, has been reported for a healthy population, aged $50-85$ years. ${ }^{18}$ However, prior studies have shown a much higher loss, at $2.0 \%-4.6 \%$ (hip BMD), the first year after hip fracture, ${ }^{3,5}$ which is consistent with the findings for the control group in the current study. Two studies reported an increase in total hip BMD after hip fracture when patients were treated with a single dose of intravenous zoledronic acid. ${ }^{13,19}$ The present study entailed bisphosphonates orally but still had bone-resorption-preventive effects compared with controls. Because absorption of orally administered treatment is low even under ideal circumstances, it could explain the lower net gain in BMD compared with the previous studies. ${ }^{13,19}$ Another important consideration is known suboptimal patient adherence with orally administered bisphosphonates, ${ }^{20,21}$ which we also observed in the current study.

To our knowledge, only a few studies have explored the possible effects of protein- and energy-rich nutritional supplements on BMD after a hip fracture. In a randomized controlled study of 60 women with femoral neck fracture, Tengstrand et $\mathrm{al}^{22}$ evaluated the effect of treatment with protein-rich supplementation alone or in combination with 
Table 2 Mean change in BMD and biochemical measurements among patients presenting for follow-up at 6 and 12 months

\begin{tabular}{|c|c|c|c|c|}
\hline Months & Group C, mean (SD), \% & Group B, mean (SD), \% & Group BN, mean (SD), \% & $P$-value* \\
\hline \multicolumn{5}{|c|}{ BMD total hip, $\mathrm{g} / \mathrm{cm}^{2}$} \\
\hline $0-6^{\dagger}$ & $-0.017(0.026),-2.4$ & $-0.008(0.037),-1.1$ & $0.005(0.026),+0.7$ & 0.071 \\
\hline $0-12^{\ddagger}$ & $-0.018(0.032),-2.6$ & $-0.012(0.042),-1.7$ & $-0.004(0.025),-0.5$ & 0.239 \\
\hline \multicolumn{5}{|c|}{ BMD total body, $\mathrm{g} / \mathrm{cm}^{2}$} \\
\hline $0-6 \pi$ & $-0.012(0.019),-1.2$ & $-0.005(0.018),-0.5$ & $-0.006(0.018),-0.6$ & 0.429 \\
\hline $0-12 * *$ & $-0.017(0.020),-1.8$ & $-0.003(0.022),-0.3$ & 0.0006 (0.019), +0.06 & 0.009 \\
\hline \multicolumn{5}{|l|}{ S-CTX-I ng/L } \\
\hline $0-12^{\ddagger}$ & $-86(291)$ & $-188(249)$ & $-145(134)$ & \\
\hline \multicolumn{5}{|l|}{$\mathrm{S}-\mathrm{CTX}-\mathrm{I}_{\mathrm{In}}{ }^{\dagger+}$} \\
\hline $0-12$ & $-0.2(0.7)$ & $-0.6(0.7)$ & $-0.6(0.5)$ & 0.055 \\
\hline \multicolumn{5}{|c|}{$\mathrm{S}-25 \mathrm{OHD}, \mathrm{nmol} / \mathrm{L}$} \\
\hline $0-12^{\pi \pi}$ & $17(22)$ & $18(37)$ & $20(24)$ & 0.730 \\
\hline \multicolumn{5}{|c|}{ S-parathyroid hormone, ng/L } \\
\hline $0-6 * * *$ & $-2.3(19.4)$ & $7.4(16.3)$ & $-8.6(17.9)$ & 0.453 \\
\hline $0-12^{t+t}$ & $3.0(18.4)$ & $-4.7(19.8)$ & $-2.2(18.2)$ & 0.494 \\
\hline
\end{tabular}

Notes: *Differences between groups were analyzed by analysis of covariance. ${ }^{\dagger}$ Missing data: BMD total hip $0-6$ months in group $C$, B, BN $=2,8,9$, respectively. ${ }^{\ddagger}$ Missing data: BMD total hip 0-12 months in group $\mathrm{C}, \mathrm{B}, \mathrm{BN}=3,8,10$. TMissing data: BMD total body 0-6 months in group $\mathrm{C}, \mathrm{B}, \mathrm{BN}=\mathrm{I}, 3,7$. **Missing data: $\mathrm{BMD}$ total body 0-12 months in group $C, B, B N=2,3,8$. ${ }^{\dagger} \mathrm{S}-C T X_{\text {In }}$ : normal distribution of $C T X$ values was achieved by transformation using a logarithmic scale. $\mathrm{C}, \mathrm{B}, \mathrm{BN}=\mathrm{I}, 3,7$. ПTMissing data: $25 \mathrm{OH}$ vitamin $\mathrm{D}$ in group $\mathrm{C}, \mathrm{B}, \mathrm{BN}=\mathrm{I}, 3,7$. ***Missing data: parathyroid hormone $0-6$ months in group $\mathrm{C}, \mathrm{B}, \mathrm{BN}=\mathrm{I}, 3,6$. $+t+$ Missing data: parathyroid hormone $0-12$ months in group $C, B, B N=3,6,9$.

Abbreviations: C, control; B, bisphosphonates; BN, bisphosphonates plus nutritional supplementation; SD, standard deviation; BMD, bone mineral density; S-CTX-I, serum C-terminal telopeptide of collagen I; S-25OHD, serum-25-hydroxy-vitamin D; S, serum.

anabolic steroids on both hip and total body BMD. Although the difference in BMD between the groups did not reach statistical significance, the results of their study indicated an increase in total body BMD at 6 and 12 months in the groups that received protein and energy supplementation compared with the group treated only with calcium and vitamin D. ${ }^{22}$ Another study of 82 hip fracture patients showed that protein supplementation ( $20 \mathrm{~g}$ daily) for 12 months after hip fracture preserved BMD when compared with untreated controls. ${ }^{9}$ The nutritional supplementation used in the current study provided a $40 \mathrm{~g}$ daily dose of protein compared with only $20 \mathrm{~g}$ in the previous studies, ${ }^{9,22}$ which may explain why the BMDpreserving effect was already observable after 6 months.

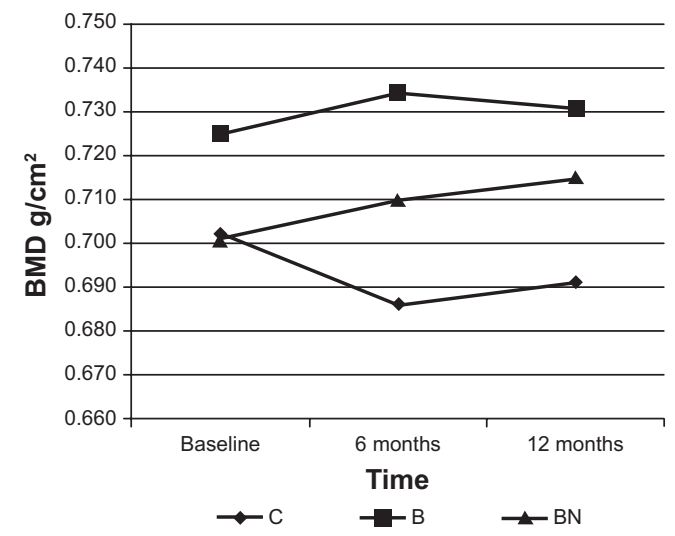

Figure 2 Total hip bone mineral density (BMD) in absolute values $\left(\mathrm{g} / \mathrm{cm}^{2}\right)$ at baseline and at follow-up.

Abbreviations: C, control; B, bisphosphonates; BN, bisphosphonates along with nutritional supplementation.
Furthermore, participants in our study were supplemented with $600 \mathrm{kcal} / \mathrm{day}$, rather than the $250 \mathrm{kcal} /$ day seen in one of the previous studies. ${ }^{9}$ Unlike previous studies, patients in the current study were also treated with drugs that inhibit bone resorption. ${ }^{9,22}$ The mean change in total hip BMD between groups at 6 months did not quite reach significance, but this may be explained by the small group size. However, the intentionto-treat analysis supported the results of complete cases and showed significant difference between groups in total hip BMD at 6 months and total body BMD at 12 months. The more rapid bone metabolic changes in total hip BMD could be a result of a larger content of trabecular bone compared with total body BMD. It may also explain the lack of

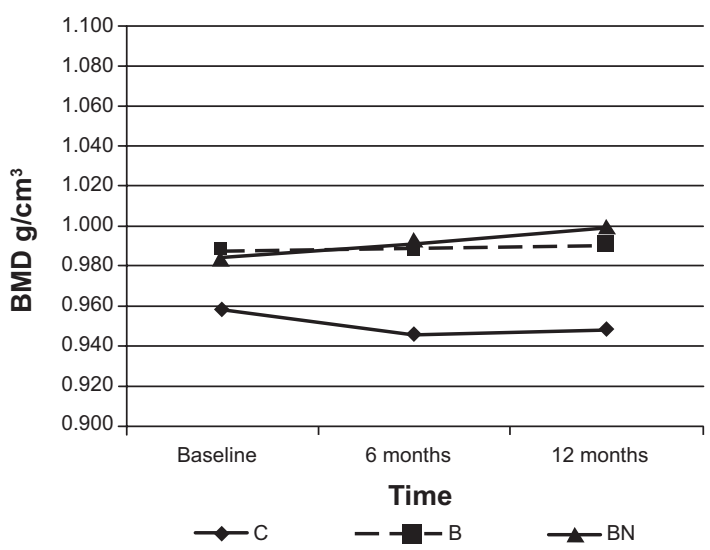

Figure 3 Total body bone mineral density (BMD) in absolute values $\left(\mathrm{g} / \mathrm{cm}^{2}\right)$ at baseline and at follow-up.

Abbreviations: C, control; B, bisphosphonates; $\mathrm{BN}$, bisphosphonates along with nutritional supplementation. 
effect on total hip BMD at 12 months because treatment with nutritional supplementation ended at 6 months. Although the study lasted for 1 year, we chose to give nutritional supplement only during the first 6 postoperative months, when the degree of catabolism is likely to be most pronounced.

We found no differences in vitamin D levels between groups to explain the disparities in BMD. All groups received vitamin $\mathrm{D}$, and mean values were normalized during the study. However, $26 \%$ of all patients included still had values less than $50 \mathrm{nmol} / \mathrm{L}$ at the final follow-up; these findings were consistent with the results from a prior study in which hospitalized women at 66-95 years of age were treated with vitamin D3 (800 IE) and calcium $(1,000 \mathrm{mg}) .{ }^{23}$ As in the current study, mean levels were normalized after treatment, but in $18(35 \%)$ of 51 patients, the levels remained low. ${ }^{23}$ Reasons proposed to explain these findings included insufficient vitamin D dose, a short supplementation period of only 3 months, and noncompliance issues. The first and last of these reasons may also apply to the current study.

The decrease in bone resorption marker serum-CTX-I levels became more pronounced in both risedronate-treated groups at 12 months. Because bone resorption-inhibiting drugs decrease CTX-I levels, these results reflect the expected treatment response to risedronate. Our baseline samples were drawn 1-3 days postfracture, which may have contributed to the variability in CTX-I levels. Other causes of variability not taken into account in the current study include food intake and circadian rhythm. ${ }^{24}$

Potential limitations of our study were the inclusion and exclusion criteria, which selected for a group of hip fracture patients who were living independently, were ambulatory on admission, were without severe cognitive dysfunction, and were slightly younger than the average age for this particular diagnosis. Group size was also a limiting factor, as was lack of compliance despite regular telephone follow-ups. The randomized design was one of the strengths of the study, as was the relatively long treatment period. Moreover, the design of the current study was novel in that it combined nutritional supplementation with bisphosphonate treatment after hip fracture in elderly men and women.

We may thereby conclude that nutritional supplementation, along with an oral administered bisphosphonate, produces additive effects on BMD after hip fracture.

\section{Acknowledgments}

The authors are grateful to research nurses Paula KellyPettersson, Bodil Samuelsson, Åsa Norling, Kristina Källbom, Elisabeth Skogman, Anita Söderqvist, and Christina
Häll and to Jan Kowalski for the assistance with statistical analysis. The study received unrestricted financial support from Stockholm County Council. The grants covered the costs of trial nurses at the four participating centers. Financial support was also provided by Karolinska Institutet funding and through the regional agreement on medical training and clinical research between Stockholm County Council and Karolinska Institutet.

\section{Disclosure}

The bisphosphonate preparation risedronate (Optinate ${ }^{\circledR}$ Septimum) was provided by Sanofi AB (Weiterstadt, Germany) and the liquid supplementation was provided by Fresenius Kabi (Bad Homburg, Germany). Sponsors were not involved in the planning or implementation of the study, nor in the analyses, conclusions, or manuscript writing. None of the authors of this manuscript has any conflict of interest regarding funding sources. All authors contributed significantly to the implementation of the study, data analysis, and manuscript writing.

\section{References}

1. Bachrach-Lindström MA, Ek AC, Unosson M. Nutritional state and functional capacity among elderly Swedish people with acute hip fracture. Scand J Caring Sci. 2000;14(4):268-274.

2. Bell J, Bauer J, Capra S, Pulle CR. Barriers to nutritional intake in patients with acute hip fracture: time to treat malnutrition as a disease and food as a medicine? Can J Physiol Pharmacol. 2013;91(6): 489-495.

3. Fox KM, Magaziner J, Hawkes WG, et al. Loss of bone density and lean body mass after hip fracture. Osteoporos Int. 2000;11(1):31-35.

4. Hedström M. Hip fracture patients, a group of frail elderly people with low bone mineral density, muscle mass and IGF-I levels. Acta Physiol Scand. 1999;167(4):347-350.

5. Karlsson M, Nilsson JA, Sernbo I, Redlund-Johnell I, Johnell O, Obrant KJ. Changes of bone mineral mass and soft tissue composition after hip fracture. Bone. 1996;18(1):19-22.

6. Darling AL, Millward DJ, Torgerson DJ, Hewitt CE, Lanham-New SA Dietary protein and bone health: a systematic review and meta-analysis. Am J Clin Nutr. 2009;90(6):1674-1692.

7. Hannan MT, Tucker KL, Dawson-Hughes B, Cupples LA, Felson DT, Kiel DP. Effect of dietary protein on bone loss in elderly men and women: the Framingham Osteoporosis Study. J Bone Miner Res. 2000; 15(12):2504-2512.

8. Meng X, Zhu K, Devine A, Kerr DA, Binns CW, Prince RL. A 5-year cohort study of the effects of high protein intake on lean mass and BMC in elderly postmenopausal women. J Bone Miner Res. 2009; 24(11):1827-1834.

9. Schürch MA, Rizzoli R, Slosman D, Vadas L, Vergnaud P, Bonjour JP. Protein supplements increase serum insulin-like growth factor-I levels and attenuate proximal femur bone loss in patients with recent hip fracture. A randomized, double-blind, placebo-controlled trial. Ann Intern Med. 1998;128(10):801-809.

10. McClung MR, Geusens P, Miller PD, et al; Hip Intervention Program Study Group. Effect of risedronate on the risk of hip fracture in elderly women. Hip Intervention Program Study Group. N Engl J Med. 2001; 344(5):333-340.

11. Wells GA, Cranney A, Peterson J, et al. Alendronate for the primary and secondary prevention of osteoporotic fractures in postmenopausal women. Cochrane Database Syst Rev. 2008;(1):CD001155. 
12. Boonen S, McClung MR, Eastell R, El-Hajj Fuleihan G, Barton IP, Delmas P. Safety and efficacy of risedronate in reducing fracture risk in osteoporotic women aged 80 and older: implications for the use of antiresorptive agents in the old and oldest old. J Am Geriatr Soc. 2004;52(11):1832-1839.

13. Boonen S, Orwoll E, Magaziner J, et al; HORIZON Recurrent Fracture Trial. Once-yearly zoledronic acid in older men compared with women with recent hip fracture. J Am Geriatr Soc. 2011;59(11):2084-2090.

14. Lu Y, Fuerst T, Hui S, Genant HK. Standardization of bone mineral density at femoral neck, trochanter and Ward's triangle. Osteoporos Int. 2001;2(6):438-444.

15. Pfeiffer E. A short portable mental status questionnaire for the assessment of organic brain deficit in elderly patients. J Am Geriatr Soc. 1975; 23(10):433-441.

16. Andridge RR, Little RJ. A Review of Hot Deck Imputation for Survey Non-response. Int Stat Rev. 2010;78(1):40-64.

17. Moher D, Hopewell S, Schulz KF, et al. CONSORT 2010 explanation and elaboration: updated guidelines for reporting parallel group randomised trials. BMJ. 2010;340:c869.

18. Berger C, Langsetmo L, Joseph L, et al; CaMos Research Group. Association between change in BMD and fragility fracture in women and men. J Bone Miner Res. 2009;24(2):361-370.
19. Eriksen EF, Lyles KW, Colón-Emeric CS, et al. Antifracture efficacy and reduction of mortality in relation to timing of the first dose of zoledronic acid after hip fracture. J Bone Miner Res. 2009;24(7):1308-1313.

20. Burden AM, Paterson JM, Solomon DH, Mamdani M, Juurlink DN, Cadarette SM. Bisphosphonate prescribing, persistence and cumulative exposure in Ontario, Canada. Osteoporos Int. 2012;23(3): 1075-1082.

21. Cotté FE, Fardellone P, Mercier F, Gaudin AF, Roux C. Adherence to monthly and weekly oral bisphosphonates in women with osteoporosis. Osteoporos Int. 2010;21(1):145-155.

22. Tengstrand B, Cederholm T, Söderqvist A, Tidermark J. Effects of protein-rich supplementation and nandrolone on bone tissue after a hip fracture. Clin Nutr. 2007;26(4):460-465.

23. DeLappe E, McGreevy C, ni Chadhain N, Grimes H, O’Brien T, Mulkerrin E. Vitamin D insufficiency in older female communitydwelling acute hospital admissions and the response to supplementation. Eur J Clin Nutr. 2006;60(8):1009-1015.

24. Naylor K, Eastell R. Bone turnover markers: use in osteoporosis. Nat Rev Rheumatol. 2012;8(7):379-389.
Clinical Interventions in Aging

\section{Publish your work in this journal}

Clinical Interventions in Aging is an international, peer-reviewed journal focusing on evidence-based reports on the value or lack thereof of treatments intended to prevent or delay the onset of maladaptive correlates of aging in human beings. This journal is indexed on PubMed Central, MedLine,

\section{Dovepress}

CAS, Scopus and the Elsevier Bibliographic databases. The manuscript management system is completely online and includes a very quick and fair peer-review system, which is all easy to use. Visit http://www.dovepress. com/testimonials.php to read real quotes from published authors. 